\title{
REAÇÕES DE SÍNTESE DA LIPASE B DE Candida antarctica (CAL B) IMOBILIZADA EM POLIURETANO
}

\author{
I. A. FERNANDES ${ }^{1}$; N. L. D. NYARI ${ }^{1}$; A. M. M. FICANHA ${ }^{1}$; A. R. PAULAZZI ${ }^{1}$; K. \\ LEVANDOSKI $^{1}$, J. ZENI $^{1}$; R. M. DALLAGO ${ }^{1}$ \\ ${ }^{1}$ Universidade Regional Integrada do Alto Uruguai e Missões, URI- Erechim, RS, Departamento \\ de Engenharia de Alimentos \\ E-mail: ilizandrafernandes@yahoo.com
}

\begin{abstract}
RESUMO - Os ésteres de ácidos graxos representam uma das mais importantes classes de compostos orgânicos, com uma diversidade de aplicações no setor industrial de óleos e gorduras e processos para a síntese de ésteres por rota química ou enzimática. Nesse contexto o objetivo deste estudo foi avaliar a seletividade das lipases imobilizadas de Candida antarctica tipo B imobilizada por confinamento em poliuretano em relações com ácidos graxos e alcoóis na conversão em ésteres etílicos utilizados principalmente na industria de alimentos, na produção de aromas. Foram testados os alcoóis: etanol; npropanol; n-butanol; metanol e ácido butanoico; oleico e láurico, apresentando atividades significativas para oleato de etila e metila com 1469,28 U/g e 650,658 U/g. Para a síntese de butirato de etila e metila de $943,396 \mathrm{U} / \mathrm{g}$ e $2281,25 \mathrm{U} / \mathrm{g}$ e laurato de etila e propila $969,626 \mathrm{U} / \mathrm{g}$ e 1440,972 U/g. Os resultados obtidos mostram que a enzima imobilizada é capaz de catalisar reações de síntese entre álcoois e ácidos graxos de cadeia curta e longa a síntese de ésteres a partir de ácidos é importante para a geração de aroma e sabor utilizados principalmente nas indústrias de alimentos e bebidas.
\end{abstract}

\section{INTRODUÇÃO}

Os ésteres de aromas são ingredientes importantes para a obtenção de vários produtos na indústria de alimentos, e são encontrados em muitos óleos essenciais. São geralmente utilizados como compostos de sabor e fragrâncias em alimentos e bebidas, gerando aromas de produtos naturais e odor frutados (Martins, 2012).

A esterificação é o processo de obtenção de um éster a partir da reação de um ácido orgânico ou inorgânico com um álcool, pela substituição de uma hidroxila $(-\mathrm{OH})$ de um ácido por um radical alcoxíla (-OR) do álcool, com a eliminação de água (Robles Medina et al., 2009).

A reação de esterificação em condições normais é lenta, sendo necessário o uso de um catalisador. Embora esses produtos possam ser obtidos por método químico, que utiliza catalisadores mais agressivos, desenvolvimentos recentes nas últimas décadas mostram que os métodos de esterificação enzimáticos com o uso de biocatalisadores, principalmente as lipases, mostram-se cada vez mais propulsor na síntese de ésteres de aromas (Aragão et al., 2010; Bezbradica et al., 2007). 


\section{9 a 22 de outubro de 2014 \\ Florianópolis/SC}

Os biocatalisadores proporcionam vantagens ambientais, condições leves de reação, alta eficiência catalítica, seletividade inerente de catalisadores e, além disso, o produto obtido na reação pode ser considerado como "naturais" (Pires-Cabral et al., 2007; Martins, 2012).

A enzima lipase de Candida antarctica tipo B (CAL-B) é um excelente catalisador para vários tipos de reações, dentre elas, a esterificação(Oterra e Nishikido, 2009).

Um dos principais problemas em utilizar enzimas livres em meios orgânicos é por serem moléculas solúveis, com certa flexibilidade, estrutura catalítica ordenada, delicada e frágil. Se a molécula da enzima absorve muita energia, ela pode sofrer mudanças conformacionais nos seus sítios ativos, muitas vezes irreversíveis, podendo até desnaturar totalmente enzima. Para este problema ser resolvido é necessário utilizá-la na forma imobilizada (Ozyilmaz e Gezer, 2010).

Desta forma, observa-se um crescente aumento na utilização da técnica de imobilização de enzimas dentro do campo da biotecnologia aplicada. As enzimas imobilizadas aumentam o número de moléculas por unidade de área e, consequentemente, a eficiência da reação. Além disso, as vantagens incluem também a reutilização da enzima, permitindo o seu uso contínuo; o aumento das propriedades cinéticas que melhora o controle do processo catalítico; e o aumento da estabilidade (Dalla-Vecchia et al., 2004; Garcia-Galan et al., 2008).

Os poliuretanos são bem conhecidos por sua versatilidade e capacidade para imobilizar as enzimas. Nesse contexto, o objetivo deste estudo foi avaliar a seletividade das lipases de Candida antarctica tipo B imobilizada por confinamento em poliuretano na catálise de reações para síntese enzimática dos ésteres em reações de esterificação de etil, metil, butil, propiloleato; butirato e laurato, utilizados principalmente na industria de alimentos na produção de aromas, sendo testados como substratos os alcoóis: etanol (C2); n-propanol (C3); n-butanol (C4); metanol e os ácidos butanóico (C4 - butirico); oleico (C18) e láurico (C12).

\section{MATERIAL E MÉTODOS}

\subsection{Polimerização e Imobilização}

A reação de polimerização para obtenção do poliuretano (PU) foi realizada variando a razão dos monômeros poliol:isocianato (6:4 (v/v)), segundo metodologia de Silva et al., (2013) modificada em relação a concentração dos mesmos.

O procedimento de imobilização da enzima CAL B em PU foi realizada na concentração préestabelecida da etapa anterior, onde $10 \%$ da enzima diluída foi adicionada ao monômero (Poliol) sendo homogeneizado e em seguida adicionado o isocianato. Após a etapa de polimerização, o poliuretano contendo a enzima (imobilizado) foi mantido durante 24 horas em dessecador para equalização do teor de umidade, para posterior medida da atividade por esterificação, comparando a enzima na sua forma livre. 


\section{9 a 22 de outubro de 2014 \\ Florianópolis/SC}

\subsection{Determinação da Atividade de Esterificação}

A atividade de esterificação das foi realizada pela quantificação da reação de síntese do ácido (C4 - butílico; C18 - oleico e C12 - láurico) e do álcool (C2 - etanol; C3 - n-propanol; C4 - n-butanol e metanol e ácido butanóico (C4 - butílico) na razão molar $1: 1(\mathrm{v} / \mathrm{v})$. A reação foi conduzida a $40{ }^{\circ} \mathrm{C}$, $160 \mathrm{rpm}$ por $40 \mathrm{~min}$. Esta foi iniciada pela adição da enzima $(0,1 \mathrm{~g})$ ao meio reacional, em frascos de vidro com tampa, mantidos em agitador orbital. Alíquotas de $500 \mu \mathrm{L}$ foram retiradas do meio reacional em triplicata no início da reação. A cada amostra foram adicionados $15 \mathrm{~mL}$ de uma solução de acetona-etanol (1:1) (v/v) para paralisar a reação e para extração de éster de oleato de etila segundo Paroul et al (2010 e 2011). A quantidade de ácido consumida foi determinada por titulação com $\mathrm{NaOH} 0,05 \mathrm{M}$ até pH 11.

Uma unidade de atividade enzimática foi definida como a quantidade de enzima que consome $1 \mu \mathrm{mol}$ de ácido graxo por minuto, nas condições do ensaio. A atividade enzimática foi calculada baseando em Brígida et al., 2010).

\subsection{Determinação do Rendimento}

O rendimento do imobilizado foi calculado pela porcentagem da razão da atividade total da enzima livre em solução utilizado na imobilização e da atividade total do imobilizado (o qual considera a massa total de imobilizado produzido).

\section{RESULTADOS E DISCUSSÕES}

Os resultados das reações de esterificação estão apresentados na Figura 1. Pode-se observar que o uso de ácido butírico na reação de síntese apresenta atividades de esterificação mais elevadas em comparação aos outros ácidos graxos. Para este ácido, a utilização de etanol, metanol e butanol como substratos apresentaram as maiores atividades (943,40, 2281,25 e 832,05 U/g, respectivamente). Resultados semelhantes a este foram observados utilizando etanol e metanol quando colocados em reação de síntese com o ácido oleico (1469,28 e 650,66 U/g) respectivamente. O ácido láurico também foi testado, porém, a enzima imobilizada apresentou atividades menores se comparados aos outros ácidos graxos, porém as maiores atividades foram para o etanol e propanol $(969,63$ e 1440,97 $\mathrm{U} / \mathrm{g}$ ). Resultados excelentes quando relacionados ao tempo de reação que foi de apenas $40 \mathrm{~min}$ apresentados na Figura 1. 


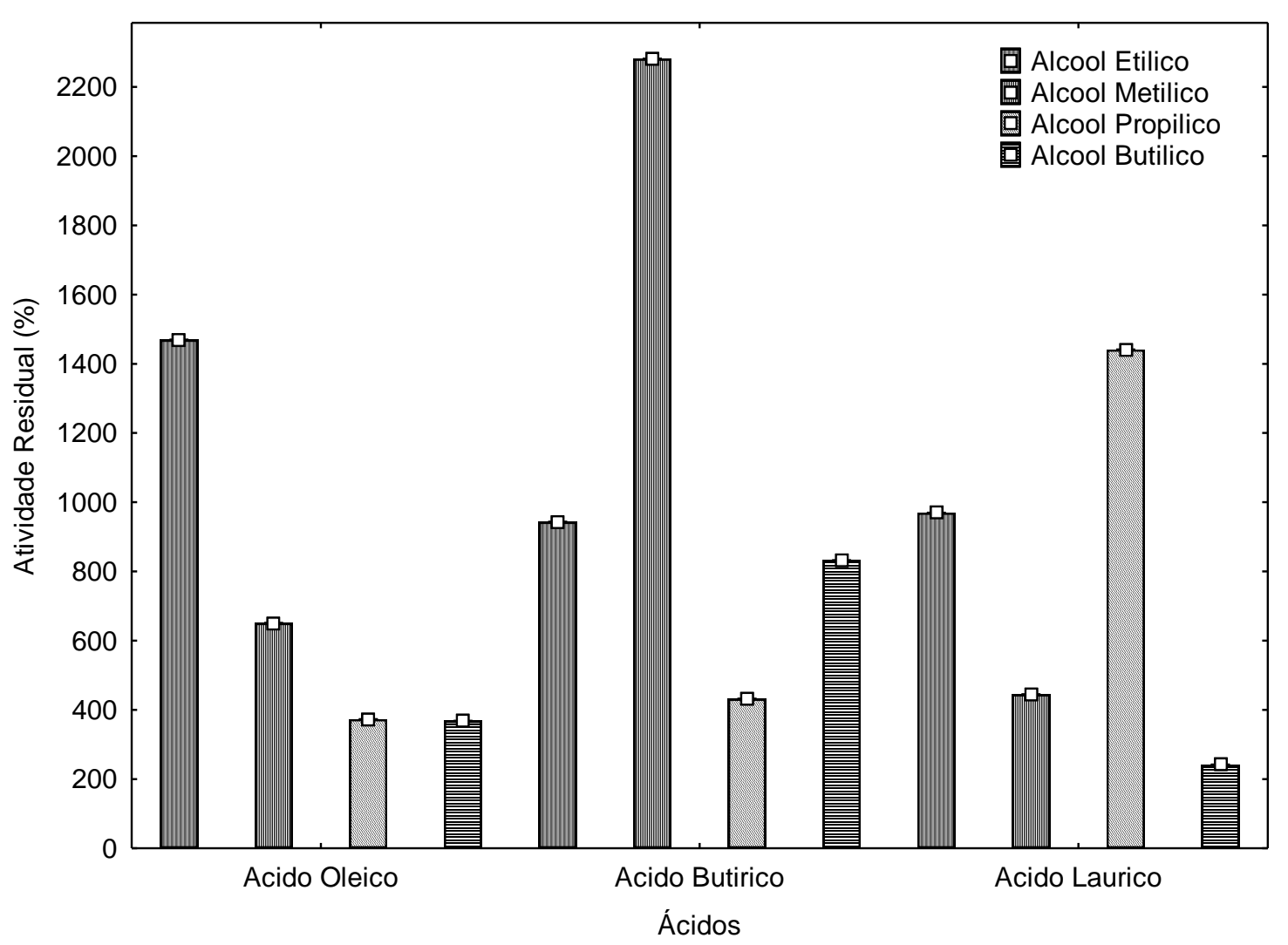

Figura 1 - Comportamento da enzima Candida antarctica B imobilizada em suporte de Poliuretano em diferentes reações de Síntese.

Em um contexto geral as menores atividades em todos os ácidos graxos estudados foram observadas para o acido láurico utilizando o álcool butanol com apenas $241,74 \mathrm{U} / \mathrm{g}$ de atividade. Comportamento semelhando teve o acido oleico com os alcoóis propanol e butanol com 372,87 e $367,74 \mathrm{U} / \mathrm{g}$ respectivamente. Indicando que a enzima imobilizada possui uma maior especificidade aos ácidos graxos de cadeia longa insaturada em comparação com saturado e alcoóis de cadeia com baixo teor de carbono.

Os produtos resultantes de ácidos e alcoóis de cadeia curta (2-8 átomos de carbono) são importantes componentes de aromas e flavorizantes utilizados nas indústrias de alimentos, bebidas, cosméticos e medicamentos. Já os produtos de esterificação de ácidos carboxílicos de cadeia longa (12-20 átomos de carbono) com alcoóis de cadeia longa são utilizados como lubrificantes. Os ésteres resultantes das reações entre ácidos de cadeia longa com alcoóis de cadeia curta (2-8 átomos de carbono) são utilizados nas indústrias como aditivos em alimentos, detergentes, cosméticos (Güvença et al., 2002). Os ésteres de ácidos graxos de cadeia longa são os principais constituintes do biodiesel, sendo assim podemos observar que a atividade enzimática é fortemente afetada pela escolha do solvente orgânico, que pode provocar a desnaturação da enzima levando à perda da atividade do catalisador (Hazarika et al., 2002). 


\section{9 a 22 de outubro de 2014 \\ Florianópolis/SC}

Souza (2013) em seu estudo imobilizando a lipase de Candida antarctica do tipo B (CALB) em nanopartículas magnéticas de ferro na catálise dos ésteres: oleato de etila (biodiesel), butirato de metila e etila, obteve-se conversão para o etiloleato de aproximadamente $90 \%$ para ambos os biocatalisadores sob temperatura de $60{ }^{\circ} \mathrm{C}$ em 48 h de reação. Sendo assim, a máxima a conversão de butirato de etila $(96,8 \%)$ e metila $(93,9 \%)$ utilizando o heptano como solvente foram obtidos a $25{ }^{\circ} \mathrm{C}$ com CALB imobilizada em nanopartículas magnéticas após 8 h de reação.

Os estudos na literatura (Aragão et al., 2010; Grosso et al., 2012) apresentam a utilização de várias lipases imobilizadas para a produção de butirato de etila. Valdez-Peña et al., 2010) realizou a catálise de ácido butírico e etanol por resina acrílica Novozym ${ }^{\circledR} 435 \mathrm{em} 10 \mathrm{ml}$ de n-heptano, obteve conversão de $75 \%$ em 96 horas. A taxa de conversão de $88 \%$ de butirato de etila foi obtida por Aragão et al. (2010), em 3 h de reação, $40 \mathrm{ml}$ de volume reacional, utilizando lipase de Mucor miehei imobilizada em pérolas de resina comerciais.

Dalla-Vecchia et al. (2004) testaram as lipases de diferentes procedências imobilizadas em filmes de carboximetilcelulose (CMC), álcool poli-vinílico (PVA) e blendas de CMC/PVA em reações de esterificação do ácido láurico com o n-pentanol. Os ésteres foram obtidos com conversões de até $99 \%$, comprovando a eficiência desses biocatalisadores.

Madalozzo (2011) utilizou a lipases de Rhizopus oryzae na imobilização em suporte hidrofóbico (Accurel MP-1000) na realização de síntese do oleato de etila obtendo em $1 \mathrm{~h}$ de reação conversão em éster de 93\% em com ilizando-se $70 \mathrm{U}$ de atividade de hidrólise contra a trioleína (3537 mg.h-1.gcat1) com conversão de $96 \%$ obtida em 0,5 h. Com o aumento de 10 vezes a quantidade de substratos em relação aos estudos preliminares a produtividade do oleato de etila quadriplicou (7200 mg.h-1.gcat-1) com uma conversão de $76 \%$ em 0,5 h.

\section{CONCLUSÕES}

Os resultados obtidos mostram que a enzima imobilizada é capaz de catalisar reações de síntese entre álcoois e ácidos graxos de cadeia curta (ácido butírico) e longa (ácido oleico). A síntese de ésteres a partir de ácidos é importante para a geração de aroma utilizados principalmente nas indústrias de alimentos e bebidas. Os ensaios apresentaram atividade para oleato de etila com 1469,28 U/g e para a síntese de butirato de etila e metila de 943,396 U/g e 2281,25 U/g e laurato de etila e propila 969,626 U/g e 1.440,972 U/g. As altas produtividades obtidas neste trabalho indicam que a lípase B Candida antarctica imobilizada em suporte de poliuretano possui um bom potencial para aplicação em processos biocatalíticos em meio orgânico, mostrando que é necessário um estudo mais aprofundando, variando temperatura, tempo e razão molar tanto para o acido, álcool e concentração de enzima, a fim de otimizar o processo.

\section{REFERÊNCIAS BIBLIOGRÁFICAS}

ARAGÃO, V. C.; PORTO, M. R. A.; BURKERT, C. A. V.; KALIL, S. J.; BURKERT, J. F. D. M. Response surface methodology approach for the synthesis of ethyl butyrate. Food Technol. Biotech. v. 49, p. 103-110, 2010. 
BEZBRADICA, D.; MIJIN, D. S.; SILER-MARINKOVI, S.; KNEZEVIC, Z. The effect of substrate polarity on the lipase-92 catalyzed synthesis of aroma esters in solvent-free systems. $J$. Mol. Catal. B: Enzym., v. 45, p. 97-101, 2007.

BRÍGIDA, A. I. S.; CALADO, V. M. A.; GONÇALVES, L. R. B.; COELHO, M. A. Z. Effect of chemical treatments on properties of green coconut fiber. Carbyd. Polym. v. 79, p. 832-838, 2010.

DALlA VECCHIA, C.; BOWER, R. G.; THEUNS, T.; BALOGH, M. L.; MAZZOTTA, P., FRENK, C. S. Quenching cluster cooling flows with recurrent hot plasma bubbles. Mon. Not. Royal Astron. Society, v. 355, p. 995-1004, 2004.

GARCÍA-GALÁN, M. J.; DÍAZ-CRUZ, M. S.; BARCELÓ, D. Identification and determination of metabolites and degradation products of sulfonamide antibiotics. Trends Anal. Chem. v. 27, p. 1008-1022, 2008.

GROSSO, C.; FERREIRA-DIAS, S.; PIRES-CABRAL, P. Modelling and optimization of ethyl butyrate production catalysed by Rhizopus oryzae lipase. J. Food Eng, v. 115, p. 475-480, 2012.

GÜVENÇA, A.; KAPUCU, N.; MEHMETOĞLU, Ü. The production of isoamyl acetate using immobilized lipases in a solvent-free system. Process Bioche. v. 38, p. 379-386, 2002.

HAZARIKA, S.; GOSWAMI, P.; DUTTA, N.N.; HAZARIKA, A. K. Ethyl oleate synthesis by Porcine pancreatic lipase in organic solvents. Chemical Eng. J, v. 85, p. 61-68, 2002.

MADALOZZO, A. Síntese de ésteres etílicos utilizando uma lipase recombinante de Rhizopus oryzae. Dissertação (Mestrado em Ciências Bioquímica) Universidade Federal do Paraná, 2011.

MARTINS, A. B. Comparação entre agitação mecânica e ultrassônica na Síntese de ésteres de aromas catalisada por lípase. Trabalho de Conclusão (Curso de Engenharia de Alimentos) Graduação Universidade Federal do Rio Grande do Sul, 2012.

OTERRA, J.; NISHIKIDO, J. Esterification: methods, reactions, and applications. $2^{\circ}$ Edition. J. Wiley Son 363p. 2009.

OZYILMAZ, G.; GEZER, E. Production of aroma esters by immobilized Candida rugosa and porcine pancreatic lipase into calcium alginate gel. J. Mol. Catal. B: Enzym., v. 64, p. 140-145, 2010.

PAROUl, N.; BIASI, A.; ROVANI, A. C.; PRIGOL, C.; DALlAGO, R.; TREICHEL, H.; OLIVEIRA, D. Enzymatic production of linalool esters in organic and solvent-free system. Biop. Bios. Eng. v. 33, p. 583-589, 2010. 
PAROUL, N.; GRZEGOZESKI, L. P.; CHIARADIA, V.; TREICHEL, H.; CANSIAN, R. L.; OLIVEIRA, J. V.; OLIVEIRA, D. Solvent-free geranyloleate production by enzymatic esterification. Biop. Bios. Eng. v. 34, p. 323-329, 2011.

PIRES-CABRAL, P.; FONSECA, M. M. R.; FERREIRA-DIAS, S. Modelling the production of ethyl butyrate catalysed by Candida rugosa lipase immobilized in polyurethane foams. Biochem. Eng. J. v. 33, p. 148-158, 2007.

ROBLES MEDINA, R. A.; GONZALEZ, M. P. A.; ESTEBAN, C. I.; MOLINA, G. E., RoblesMedina, A., González-Moreno, P. A., Esteban-Cerdán, L., Molina-Grima, E. Biocatalysis: towards ever greener biodiesel production. Biotechnology advances, 27(4), 398-408, 2009.

SILVA, M. F.; RIGO, D.; MOSSIA, V.; DALLAGO, R. M.; HENRICK, P; KUHNA, G. O.; DE, ROSA, D. C.; OLIVEIRA, D.; OLIVEIRA, J. V.; TREICHEL, H. Evaluation of enzymatic activity of commercial inulinase from Aspergillus niger immobilized in polyurethane foam. Food Biop. Process. v. 91, p. 54-59, 2013.

SOUZA, M. C. M. de. Imobilização de lipase de Candida antarctica do tipo B em nanopartículas magnéticas visando a aplicação na síntese de ésteres. Tese (Doutorado em Engenharia Química) Universidade Federal do Ceará, 2013.

VALDEZ-PEÑA， A. U.; ESPINOZA-PEREZ， J. D.; SANDOVAL-FABIAN， G. C.; BALAGURUSAMY, N.; HERNANDEZ-RIVERA, A.; DE-LA-GARZA RODRIGUEZ, I. M.; CONTRERAS-ESQUIVEL, J. C. Screening of industrial enzymes for deproteinization of shrimp head for chitin recovery. F. Scie. Biotechn. v. 19, p. 553-557, 2010. 